Copyright by the American Society of Agricultural and Biological Engineers. Rosenquist, S. E.; Levy, C. L.; Sell, S. T.; Hession, W. C.; Eick, M. J.; Vaughan, D. H., "Facilitated iron reduction as a possible means of rejuvenating phosphorus removal performance of filtration substrates," Transactions of the ASABE. 54(2): 715-722. (doi: 10.13031/2013.36474)@2011

\title{
Facilitated Iron Reduction as a Possible Means of Rejuvenating Phosphorus Removal Performance of Filtration Substrates
}

\author{
S. E. Rosenquist，C. L. Levy，S. T. Sell，W. C. Hession， M. J. Eick，D. H. Vaughan
}

\begin{abstract}
In order to mitigate nutrient pollution in surface runoff more sustainably, the finite capacity for phosphorus $(P)$ sequestration in best management practices (BMP) that rely heavily on sorption processes must be addressed. These BMP include sand filters, bioretention cells, and several types of constructed wetland. This study investigated facilitated microbial reduction of iron-based filtration substrates to promote controlled release of P previously sequestered by the BMP, $P$ harvest for recycling, and rejuvenation of the substrate sorption capacity. Total dissolved $P$ was well correlated with total dissolved iron during the reduction process, indicating that microbial iron reduction was capable of releasing previously sequestered $P$ from substrates. Furthermore, results indicated that a sufficient carbon source was necessary but addition of a microbial culture was not necessary to facilitate iron reduction. While a large percentage of the previously sequestered $P$ was removed, the process was much slower than initial sequestration of $P$ by adsorption, and further research is needed to promote a more rapid release of $P$ in order to optimize the rejuvenation process for field application.
\end{abstract}

Keywords. Best management practices, Desorption, Eutrophication, Filtration, Phosphorus, Sorption, Water quality.

$\mathrm{E}$ xcess phosphorus $(\mathrm{P})$ has long been associated with eutrophication, which can diminish overall water quality. Algal blooms are typically the most obvious result of excess $\mathrm{P}$ loading. The eventual decay of these algal blooms can cause a temporary but significant decrease in dissolved oxygen. As a result, many aquatic species can become oxygen-starved, causing various negative impacts including direct fish kills (Novotny, 2003). Various anthropogenic practices associated with agriculture, urban development, and waste management can contribute to eutrophication (Hogan and Waldbridge, 2007). While point sources of pollution (e.g., wastewater treatment plants) have historically been the largest target for remediation, nonpoint sources including urban stormwater runoff have recently been receiving increased attention as a significant contributor to excess P loading (Novotny, 2003; Baker et al., 2007).

Submitted for review in December 2009 as manuscript number BE 8345; approved for publication by the Biological Engineering Division of ASABE in January 2011.

The authors are Shawn E. Rosenquist, ASABE Member, Graduate Research Assistant, Department of Biological Systems Engineering, Virginia Tech, Blacksburg, Virginia; Cherona L. Levy, Undergraduate Research Assistant, Department of Environmental Engineering Sciences, University of Florida, Gainesville, Florida; Steven T. Sell, ASABE Member Engineer, Undergraduate Research Assistant, Department of Biological Systems Engineering, University of Wisconsin, Madison, Wisconsin; W. Cully Hession, ASABE Member Engineer, Advising Professor, Department of Biological Systems Engineering, Matthew J. Eick, Advising Professor, Department of Crop and Soil Environmental Sciences, and David H. Vaughan, Advising/Funding Professor, Department of Biological Systems Engineering, Virginia Tech, Blacksburg, Virginia. Corresponding author: Shawn E. Rosenquist, Research Scientist, Southeastern Natural Sciences Academy, 1858 Lock and Dam Rd., Augusta, GA 30906: phone: 706-828-2109; email: rosenquist@naturalsciencesacademy.org.
Water treatment processes found in natural wetlands have been effectively utilized in constructed wetlands (CW), bioretention cells, and many other best management practices (BMP) that provide effective, economical, and ecologically sound methods for managing surface water quality problems (Tenenbaum, 2004). Natural interactions within the water column, vegetation, substrates, and microbial populations function together to alleviate these environmental impacts (Hammer, 1992). However, neither natural wetlands nor CW have demonstrated a limitless and non-diminishing capacity for P sequestration (Coveney et al., 2002; Drizo et al., 2002; Kadlec, 2005; Aldous et al., 2007). Since the P cycle has no dominant gas phase, $\mathrm{P}$ removed by BMP will accumulate, mostly in organic or sediment-bound forms (White et al., 2008).

$\mathrm{P}$ removal by sorption to substrates has been cited as a major contributor to the sequestration capacity of $\mathrm{CW}$, along with biological uptake by macrophytes and microbes (Lantzke et al., 1998; Keppler and Martin, 2008). While the relative contributions of these mechanisms may differ depending on the specific characteristics of the BMP (Lantzke et al., 1999; Luederitz and Gerlach, 2002), together they generally represent most of the $P$ sequestration potential. In any case, once equilibrium is reached between adsorbed and dissolved P (Rosenquist et al., 2010), and plant uptake reduces upon sufficient grow-in (Kadlec, 2005), P sequestration performance can significantly decline. Long-term removal may continue to occur based on accretion of organic sediments, but the percentage of $\mathrm{P}$ retained in this way is small, the land requirement large, and the process, while sustainable, is less applicable for areas of high land value (Hunt and Wossink, 2003; Keppler and Martin, 2008; Kadlec and Wallace, 2009). While some scenarios have been proposed to completely remove previously sequestered $\mathrm{P}$ from the BMP, such as biomass harvesting or substrate replacement (Drizo et al., 2002; 
Kadlec, 2005), these strategies have significant drawbacks, such as the cost of continuously harvesting biomass or physically excavating and replacing sediments, the difficulty of accessing a site once construction is complete and substrates are saturated, and the low efficiency of $\mathrm{P}$ removal by biomass harvesting (Vymazal, 2005).

The lifespan for P management by $\mathrm{CW}$ is dependent upon many factors both internal (substrate sorption capacity, redox potential, biota) and external (concentration and form of influent P) to the BMP (Aldous et al., 2007). While the amount of particulate $P$ retained in a wetland is influenced by physical processes such as sediment deposition, sequestration of dissolved $\mathrm{P}$ requires either plant uptake or sorption to substrates (Aldous et al., 2007). Sorption to sediments can be affected by various geochemical and biological interactions with iron $(\mathrm{Fe})$, aluminum $(\mathrm{Al})$, and calcium $(\mathrm{Ca})$ in $\mathrm{CW}$ substrates, while plant uptake of $\mathrm{P}$ can be limited by seasonal growth patterns, eventual grow-in, and by the rate of uptake (Kadlec, 2000). Substrates not only provide physical support for macrophytes and microbial biofilms but also provide sorption capacity with $\mathrm{Fe}$ and $\mathrm{Al}$ oxyhyrdroxides. $\mathrm{P}$ removal by sorption processes is less seasonally dependent than plant uptake and can sequester dissolved $\mathrm{P}$ at a much higher rate (Hammer, 1992; Lantzke et al., 1998; Kadlec, 2005; Keppler and Martin, 2008). P removal rates tend to be highest in substrates rich in calcium, $\mathrm{Fe}$, and $\mathrm{Al}$ due to their high adsorption capacity (Luederitz et al., 2001), with calcium-rich substrates demonstrating more efficacy at higher $\mathrm{pH}$ and $\mathrm{Fe} / \mathrm{Al}-$ rich substrates at lower $\mathrm{pH}$ (McBride, 1994).

Sorption reactions include both adsorption and precipitation/coprecipitation processes that can occur between particular ions, in this case $\mathrm{P}$, and the surface of the mineral substrate. Adsorption occurs when $\mathrm{P}$ is exchanged at the mineral substrate and pore water interface and forms complexes on the mineral surface (McBride, 1994). Adsorption can be separated into outer-sphere (weakly bound) and inner-sphere (tightly bound) complexes, where the latter may also be described as chemisorption or specific adsorption (McBride, 1994), which is of the most interest for stormwater treatment since it is less reversible. $\mathrm{P}$ has a strong interaction with sites on $\mathrm{Fe}$ and $\mathrm{Al}$ oxyhydroxides; as a result, many $\mathrm{Fe}$ and $\mathrm{Al}$ oxyhydroxide minerals have a high $\mathrm{P}$ adsorption capacity (Wilson et al., 2004). Although specific adsorption is favored between $\mathrm{P}$ and $\mathrm{Fe}$ oxyhydroxides, this behavior is also strongly affected by the amount of $\mathrm{P}$ already adsorbed (Zhang and Huang, 2007) and by the number of available sorption sites in general, since the mineral surface becomes relatively inactive once adsorbents adhere to it (Wilson et al., 2004). The $\mathrm{pH}$ of the substrate environment is another factor that can influence the rate of specific adsorption of $\mathrm{P}$ with Fe oxyhydroxides (Griffioen, 2006; Rosenquist et al., 2010). Variability in sorption capacity can also occur based on physical properties; substrates with a significant amount of clay-sized particles tend to yield a higher sorption capacity due to the high specific surface area present (McGechan and Lewis, 2002). This physical property dependence can create a critical limitation to sorption capacity, especially when higher hydraulic conductivities are desired.

While sorption reactions involving $\mathrm{P}$ and $\mathrm{Fe}$ are often favored thermodynamically in $\mathrm{CW}$ environments, there are limitations and specific circumstances where net desorption has been known to occur. Weakly bound $\mathrm{P}$ can be released from the reactive sites on sand or gravel by means of anion exchange (Aldous et al., 2007), especially if it is only involved in outer-sphere complexes (McBride, 1994). In addition, further release of more tightly bound $\mathrm{P}$ may occur under reducing conditions, common in $\mathrm{CW}$, where low redox potential has been shown to correlate with net release of $\mathrm{P}$ (Komatsu et al., 2006). In an aerobic environment, the association formed between the $\mathrm{P}$ and the oxide mineral tends to be relatively insoluble and immobile, but in anaerobic conditions Fe can be reduced from ferric $\left(\mathrm{Fe}^{3+}\right)$ to ferrous $\left(\mathrm{Fe}^{2+}\right)$, allowing the $\mathrm{P}$ to be removed from the substrate (Brady and Weil, 2002). While this process has been known to occur in $\mathrm{CW}$ and can be detrimental to overall treatment performance (Carleton et al., 2000), if the redox potential of the system were more closely controlled, the Fe reduction process may be useful for rejuvenation of the sorption capacity of the substrate. Since Fe has been shown to provide much of the sorption capacity in substrates at neutral $\mathrm{pH}, \mathrm{Fe}$-based substrates may be able to release much of their previously sequestered $P$ in a facilitated iron reduction cycle.

The primary means of Fe reduction in natural wetlands is through microbial metabolism (Lovely et al., 1991). Fereducing microorganisms support their energy needs through an oxidation/reduction process involving an electron donor (organic carbon) and a terminal electron acceptor (Fe oxyhydroxides) (Scheibe et al., 2006). The release of $\mathrm{P}$ is facilitated by the ease with which the Fe is reduced and then dissolved by serving as the terminal electron acceptor. A study of Mediterranean agricultural soils showed that with the aid of $\mathrm{Fe}-$ reducing microorganisms, $\mathrm{Fe}^{3+}$ was reduced to $\mathrm{Fe}^{2+}$, facilitating the release of $\mathrm{P}$ under anoxic, continuous-flow conditions (Saavedra and Delgado, 2005). While this biotic reduction and $\mathrm{P}$ release process proceeds much more slowly under natural conditions than $\mathrm{P}$ sequestration by adsorption, the kinetics might be enhanced by providing optimal environmental conditions for microbial metabolism. For example, the reduction process may be accelerated by the presence of humic substances such as polyphenols that serve as an electron shuttle and abiotically reduce Fe (McBride, 1994).

Once Fe reduction has occurred and previously sequestered $\mathrm{P}$ has been released into solution, it must be removed completely from the BMP for recycling. At least two possibilities exist: (1) the high-P, high-Fe solution can be removed for use as a liquid fertilizer, or (2) a precipitation reaction can be facilitated, causing a stable Fe/P solid to be formed, which can be flocculated and removed for use as a fertilizer. In either case, $\mathrm{P}$ is harvested and recycled to support feedstock production, alleviating some of the need for continued mining of ever-scarcer P-rich mineral sources (Abelson, 1999).

This study is part of a larger project developing a novel BMP, the urban wetland filter (UWF) with renewable P sorption capacity for treating urban stormwater. In urban areas, high land value and limited availability of large land plots are significant obstacles to the implementation of CW (Hunt and Wossink, 2003). Required hydraulic residence time (HRT) for biological uptake and sedimentary accretion, finite pollutant assimilatory capacity, and hydraulic conductivity (in subsurface-flow wetlands only) are generally the technical limitations that cause large land areas to be required (Kadlec and Wallace, 2009). With a process to rejuvenate finite sorption capacity, the rapid kinetics of $\mathrm{P}$ removal by sorption processes can decrease required BMP space while optimizing removal of dissolved P. The UWF pairs small $\left(<140 \mathrm{~m}^{2}\right)$ wetland cells with an existing retention pond, positioning cells 
off-line from stormwater flow while they alternate between filtration and rejuvenation cycles. While the pond removes sediment-bound $\mathrm{P}$, the wetland cells are optimized for removing dissolved $\mathrm{P}$.

This study of the rejuvenation process for substrate sorption capacity addressed the following research questions: (1) Does a filtration substrate contain enough microbes to reduce Fe without the addition of a microbial culture? (2) What is the effect of a carbon source addition toward facilitating Fe reduction in the substrate versus a control without carbon source addition? (3) Will dissolved P concentrations positively correlate with dissolved Fe concentrations upon Fe reduction? (4) What percentage of previously adsorbed $P$ will be released by the Fe reduction process? and (5) How will final concentrations compare to influent concentrations observed during $\mathrm{P}$ loading?

\section{Materials ANd Methods}

This study included two complementary experimental setups. The main portion of the study took place using flowthrough wetland cells (FTWC) to investigate the central research questions with conditions approximating field installation. In addition, a set of batch reactor wetland cells (BRWC) were utilized to allow for more efficient initial evaluation of the required carbon source additions for Fe reduction, the possible need for microbial seeding, and to provide additional replicates in some cases for required statistical power.

\section{Flow-Through Wetland Cells (FTWC) Experimental Setup}

The FTWC consisted of six $20 \mathrm{~L}$ cylindrical containers filled with $25 \mathrm{~kg}$ of USDA grade medium sand media placed above a layer of limestone gravel (fig. 1). The sand, sourced from a pit mine in New Castle, Virginia, had total Fe content between $0.2 \%$ and $0.7 \%$ by mass. The $\mathrm{P}$ loading process was the main focus of another study in this research program and is described in detail by Rosenquist et al. (2010). The flow regime during P loading was from bottom to top through the gravel layer then the sand. The gravel layer served to distribute flow throughout the sand and promote piston-type flow. The filter medium was saturated throughout the loading process, but flow was intermittent and characterized by a $20 \mathrm{~h}$ flow period followed by no-flow periods of varying duration. Influent concentrations during $\mathrm{P}$ loading were between 0.1 and $0.6 \mathrm{mg} \mathrm{L}^{-1}$. During the reduction/reaction period con-

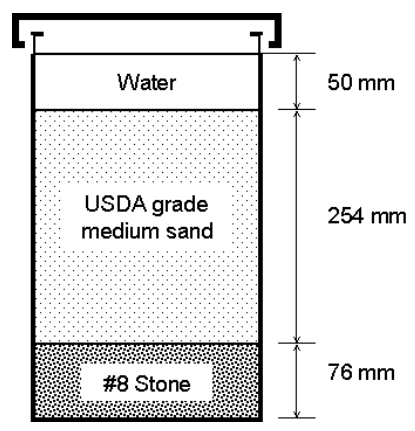

Figure 1. FTWC cross section showing layers of gravel, sand, and standing water. ducted in this study, the cells were covered with opaque lids to minimize evaporation and algal growth.

\section{Experimental Design}

The FTWC were divided into two treatment groups with three replications. For a control group (cells 1 to 3 ), no additional carbon source was added, while the experimental treatment group (cells 4 to 6) involved exchanging the water in the FTWC with a sucrose solution carbon source by flowthrough over a $2 \mathrm{~h}$ period. The final concentration of sucrose in the FTWC was between 100 and $150 \mathrm{mg} \mathrm{L}^{-1}$, depending on the extent of the pore water exchange.

\section{Sampling and Sample Analysis Procedures}

Samples were taken from the standing water at the top of each bucket in $20 \mathrm{~mL}$ volumes at the time of carbon addition and initially at $1 \mathrm{~d}$ intervals. After temporal trends were established, sampling intervals were increased to between 3 and $7 \mathrm{~d}$. Overall, 306 samples were taken from the six FTWC over a $253 \mathrm{~d}$ period. Differentiation of dissolved constituents for sample analysis was only by gravimetric settling in the FTWC, as samples were not filtered in this portion of the study. All samples were analyzed by inductively coupled plasma atomic emission spectroscopy (ICP-AES) in accordance with EPA Method 200.7 (USEPA, 1994) to determine total dissolved phosphorus (TDP) and total dissolved iron (TDI) for each sample. Along with the above sampling schedule, $\mathrm{pH}$ was measured with a handheld $\mathrm{pH}$ meter (Hanna Instruments, Woonsocket, R.I.) and dissolved oxygen was measured with a handheld dissolved oxygen meter (YSI, Inc., Yellow Springs, Ohio). Dissolved oxygen served as a surrogate for estimating gross changes in redox potential. Periodic calibrations of the $\mathrm{pH}$ and dissolved oxygen instruments were conducted in accordance with the manufacturers' instructions.

\section{Data Analysis}

Graphical analysis was conducted for each of the following variables: $\mathrm{pH}$, dissolved oxygen, TDP, TDI, and the correlation between TDP and TDI. After a distinct break in the TDP/TDI correlation was observed, including two linear regions of differing slope, a least-squares breakpoint analysis was performed to determine the threshold concentration between the two linear regions. This procedure was followed by a segmented linear regression analysis using a model with an indicator variable for the breakpoint between the two slope regions. This process tested for a correlation between Fe reduction and release of previously adsorbed $\mathrm{P}$ into solution, and for differences in the slope observed in the two regions. Lastly, a comparison was made between the final concentrations in the carbon-treated FTWC and the influent concentrations used to load the FTWC to compare concentrations and estimate the percentage of previously adsorbed $\mathrm{P}$ that was released. Statistical analyses were performed with software from the R project (R Development Core Team, 2009). For data values below the analytical limits of the instrument, the analytical limit was used for calculations. This case only occurred for $\mathrm{Fe}$ analysis on control cells (187 of 602 values).

\section{Batch Reactor Wetland Cells (BRWC) Experimental Setup}

The BRWC consisted of thirty-six $250 \mathrm{~mL}$ Nalgene containers containing $100 \mathrm{~g}$ of USDA grade medium sand of the same type used for the FTWC setup. The sand in each BRWC 
was saturated with $\mathrm{P}$ by adding $90 \mathrm{~mL}$ of distilled water and $10 \mathrm{~mL}$ of $350 \mathrm{mg} \mathrm{L}^{-1}$ stock P solution. The BRWC were agitated for $72 \mathrm{~h}$ and dewatered by vacuum filtration. After filtration, the glass-fiber filter used was added to the dewatered sample to conserve $\mathrm{P}$ in the cell.

\section{Experimental Design}

Once saturated with $\mathrm{P}$, the $36 \mathrm{BRWC}$ were randomly separated into four experimental groups based on the carbon source provided. These carbon sources included: distilled water (control), $250 \mathrm{~g} \mathrm{~L}^{-1}$ sucrose solution, surface water grab sample from a local retention pond (with slight $\mathrm{P}$ contribution accounted for), and a $50 \%$ combination of sucrose solution and surface water sample. These groups were subdivided into 1,2 , and $3 \mathrm{~d}$ reaction times. There were three replications for each combination of carbon source and reaction time. Each BRWC had $100 \mathrm{~mL}$ of the designated carbon source added gravimetrically. Each BRWC was then capped, agitated for $30 \mathrm{~s}$, and stored in a dark, climate-controlled space.

\section{Sampling and Sample Analysis Procedures}

After the dewatering process in the BRWC, the filtrate from $\mathrm{P}$ loading was weighed for volumetric comparison to the original amount, and a sample was taken for TDP analysis. After the designated reaction time, a sample was taken from each BRWC by pipetting from the standing water on top of the substrate and filtering through $0.45 \mu \mathrm{m}$ glass-fiber filter. Additional samples were taken in the same manner from three BRWC of each carbon source type after 20 and $36 \mathrm{~d}$ reaction times. One filtered sample and one filtrate weight were lost in processing, resulting in two lost data points from the set. The remaining 59 samples were analyzed by ICPAES in accordance with EPA Method 200.7 (USEPA, 1994) to determine TDP and TDI for each sample.

\section{Data Analysis}

Three values were calculated for each of the 36 BRWC: the mass of $\mathrm{P}$ initially adsorbed, the mass of $\mathrm{P}$ released at each time interval, and the percentage of initially adsorbed $P$ released at each time interval. For data values below the analytical limits of the instrument, the analytical limit was used for calculations. This case only occurred for Fe analysis (15 of 83 values). Due to a lack of normality among residuals, a Kruskal non-parametric test was applied to the data to test for differences between means with pairwise multiple comparisons with a Bonferroni correction factor to determine which means were different. Statistical analyses were again performed with software from the $\mathrm{R}$ project ( $\mathrm{R}$ Development Core Team, 2009).

\section{Results AND Discussion \\ Flow-Through Wetland Cells (FTWC) pH Values}

Both the carbon-treated cells and the control cells initially displayed near-neutral $\mathrm{pH}$; the carbon-treated cell $\mathrm{pH}$ dropped significantly and remained low throughout the study, while the control cell $\mathrm{pH}$ rose initially and then fell slightly (fig. 2a). Although slight fluctuations in $\mathrm{pH}$ were noted among cells within the control group and the treatment group, there was a much more noticeable difference between groups. Control cells consistently exhibited higher $\mathrm{pH}$ than treatment cells, which may be an indication of redox pro- cesses and microbial activity. The direction of $\mathrm{pH}$ change was somewhat unexpected, since reduction reactions as a whole tend to increase $\mathrm{pH}$ toward 7.0 (McBride, 1994). However, research has shown that under organic-rich conditions microbial fermentation exceeds respiration, resulting in the production of simple organic acids (e.g., acetate, formate) (McMahon and Chapelle, 1991). Based on the concentration of sucrose added to the system, it is assumed that the production of these organic acids was responsible for the $\mathrm{pH}$ drop observed in our experiments (pka acetate $=4.75$ and pka formate $=3.75)$. This observed decrease in $\mathrm{pH}$ may explain some of the initial decrease in TDP discussed under TDP results. The loss of dissolved oxygen and $\mathrm{pH}$ data for a threeweek period near the middle of the study explains the gaps seen in figures $2 \mathrm{a}$ and $2 \mathrm{~b}$.

\section{Dissolved Oxygen}

Dissolved oxygen concentrations can be a good indicator of substrate redox condition since, according to McBride (1994), the dominance of microbial activity transitions from aerobic to anaerobic processes when dissolved oxygen concentrations reach trace levels. Initially, both the control and carbon-treated cells had dissolved oxygen concentrations near $8 \mathrm{mg} \mathrm{L}^{-1}$, but the carbon-treated cells reached dissolved oxygen content near $2 \mathrm{mg} \mathrm{L}^{-1}$ within a few days (fig. 2b). Concentrations near $2 \mathrm{mg} \mathrm{L}^{-1}$ probably do not represent trace levels, but three factors must be considered: (1) measurements were taken at the top of the reactor and may not be representative of pore water throughout the FTWC, (2) the instrumentation used in this study for dissolved oxygen is useful for providing gross estimates and comparisons and likely provides better precision than accuracy, and (3) Fe may have been reduced in the presence of some dissolved oxygen by soluble organics (McBride, 1994). The control cells maintained dissolved oxygen concentrations around $8 \mathrm{mg} \mathrm{L}^{-1}$ throughout the study period, although significant variation existed within this group. Especially high values seen for control cells (fig. 2b) at one point in the study were probably due to analytical error associated with insufficient warm-up time on the instrument. The procedure was corrected when the error was recognized, but all data are included. Given these factors, dissolved oxygen concentrations, and hence redox potential, became lower with the addition of a carbon source, as expected.

\section{Total Dissolved Phosphorus}

TDP steadily increased throughout the study period for the carbon-treated cells (fig. 2c), while TDP concentrations in the control cells remained low. The slight initial decrease in TDP in the treatment cells, seen in the inset of figure $2 \mathrm{c}$, was likely due to higher thermodynamic favorability for adsorption at lower $\mathrm{pH}$. A group of data seen in figure $2 \mathrm{c}$ (day 58 to day 76), corresponding to a particular run on the ICP-AES instrument, has noticeably lower values for TDP than the rest of the data, mostly likely due to analytical error. The rate of $P$ release (150 to $175 \mathrm{mg}$ over 253 days) in the cells was much slower than that for the previous P adsorption (200 to $300 \mathrm{mg}$ over 15 runs of $20 \mathrm{~h}$ duration) (Rosenquist et al., 2010). The slower P release was probably rate-limited by the biological aspect of the Fe reduction process.

\section{Total Dissolved Iron}

TDI remained constant during the study for the control cells; however, a significant increase was observed in the 

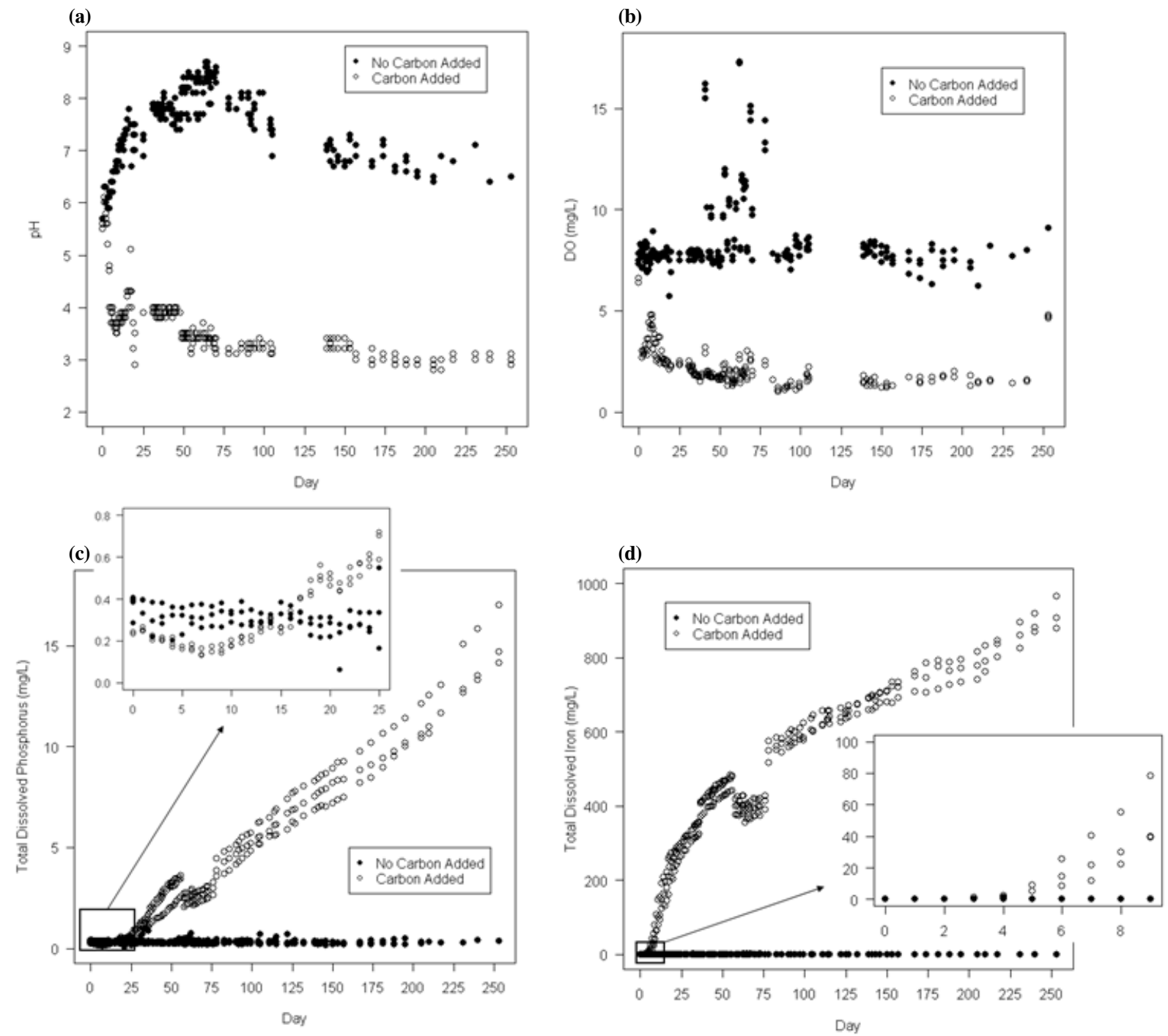

Figure 2. Trends in (a) pH, (b) dissolved oxygen, (c) TDP, and (d) TDI during the study reveal significant differences between carbon-treated and control cells.

carbon-treated cells, suggesting that the microbial reduction process was enabled by the addition of a carbon source (fig. 2d). The TDI increase in the carbon-treated cells occurred 4 to 6 days after the addition of carbon (fig. $2 \mathrm{~d}$ insert). A group of data from the same days as for TDP above (day 58 to day 76 ) appears lower in figure $2 \mathrm{~d}$, again probably due to analytical error. Apart from this, a second-order decrease in the relationship of TDI with time was observed, with an inflection point around $500 \mathrm{mg} \mathrm{Fe} \mathrm{L}^{-1}$. The change is likely due to the complete reduction of the labile Fe pool and/or some other decrease in bioavailability of $\mathrm{Fe}$ as a terminal electron acceptor.

\section{Correlation between TDP and TDI}

A graphical analysis of the correlation between TDP and TDI revealed two distinct slope regions (fig. 3). The best fit for the threshold concentration between the two slope regions in the data was $524 \mathrm{mg} \mathrm{Fe} \mathrm{L}^{-1}$, which corresponds well to the second-order decrease in TDI (fig. 2d). This result may indicate that $\mathrm{P}$ release was previously attenuated by resorption onto remaining bioavailable $\mathrm{Fe}$ before a threshold concentration of $\mathrm{Fe}$ has been reduced and $\mathrm{P}$ was allowed to increase more rapidly. Significant positive correlation exists between TDP and TDI in both slope regions, while the difference in the slopes for these regions is significant as well $(\mathrm{p}<0.05$; $\mathrm{R}^{2}=0.96$ ). For the first region, the estimated slope is 0.007 $\mathrm{mg} \mathrm{P} \mathrm{mg}{ }^{-1} \mathrm{Fe}$, while for the second region the estimated additional slope is $0.023 \mathrm{mg} \mathrm{P} \mathrm{mg}^{-1} \mathrm{Fe}$. These slopes correspond to a four-fold increase in $\mathrm{P}$ released for a given amount Fe reduced, after reaching a threshold amount of Fe reduction.

\section{Comparison of P Loading and Post-Reduction TDP Concentrations}

Comparing the TDP concentration in the carbon-treated FTWC for the last sample day (day 253) to the influent concentrations over the entire $\mathrm{P}$ loading period indicates that $\mathrm{Fe}$ reduction in this system is capable of releasing $\mathrm{P}$ at concentrations well above those present during adsorption (table 1). This result answers the fifth research question and is promising for technological feasibility of the UWF since high final concentrations are desirable for various precipitation reactions that might be utilized to harvest $\mathrm{P}$ from a filtration BMP. 


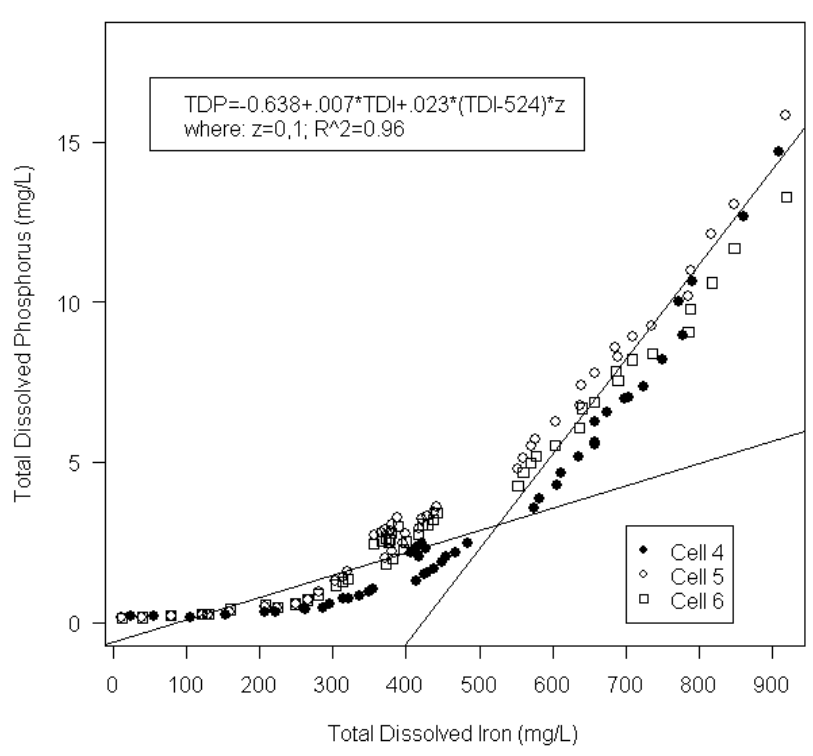

Figure 3. Correlation plot for TDP $\left(m g \mathrm{~L}^{-1}\right)$ versus TDI $\left(\mathrm{mg} \mathrm{L}^{-1}\right)$ for data after start of $\mathrm{Fe}$ reduction contains two distinct slope regions.

Table 1. Comparison of $P$ concentrations in carbon-treated FTWC.

\begin{tabular}{lcc}
\hline & $\begin{array}{c}\text { Mean } \\
\left(\mathrm{mg} \mathrm{L}^{-1}\right)\end{array}$ & $\mathrm{SD}$ \\
\hline Influent concentrations during P loading & 0.25 & 0.16 \\
Final concentration after reduction $(253 \mathrm{~d})$ & 15.3 & 1.50 \\
\hline 95\% confidence interval on percent increase $(\%)$ & \multicolumn{2}{c}{4080 to 8790} \\
\hline
\end{tabular}

Table 2. Rejuvenation percentage of FTWC with carbon additions.

\begin{tabular}{lccc}
\hline & Cell & Cell & Cell \\
& 4 & 5 & 6 \\
\hline Estimate of previously adsorbed P (mg) & 295 & 274 & 198 \\
Estimate of P in solution (mg) & 178 & 149 & 154 \\
Percent desorption of previously adsorbed P (\%) & 60.5 & 54.3 & 77.9 \\
\hline 95\% confidence interval on percent desorption $(\%)$ & \multicolumn{3}{c}{33.8 to 94.6} \\
\hline
\end{tabular}

Comparing the estimates of total mass of $\mathrm{P}$ both adsorbed and released provides an estimate of the percentage of previously adsorbed $\mathrm{P}$ released by the reduction process (table 2) and answers the fourth research question. Regarding application, this result indicates that a majority of the previously adsorbed $\mathrm{P}$ can be removed given sufficient time. This percentage can also lead to inferences about the amount of time necessary to complete the rejuvenation process. For instance, if the linearity in $\mathrm{P}$ release for the last $150 \mathrm{~d}$ of the study is assumed to continue to $90 \%$ desorption, then the entire process to release that $90 \%$ could be estimated to last 300 to $400 \mathrm{~d}$.

\section{Batch Reactor Wetland Cells (BRWC) Total Dissolved Phosphorus}

There was also a statistical difference in the means of $\mathrm{P}$ desorption in the treatment groups from the BRWC $(p=0.002$; Kruskal test). Pairwise multiple comparisons of all groups revealed that the $36 \mathrm{~d}$ sugar solution treatment and the $36 \mathrm{~d}$ sugar solution and surface water treatment were significantly different from the other treatments (fig. 4), indicating that a carbon-source addition in excess of that available from the surface water sample was necessary to drive Fe reduction.

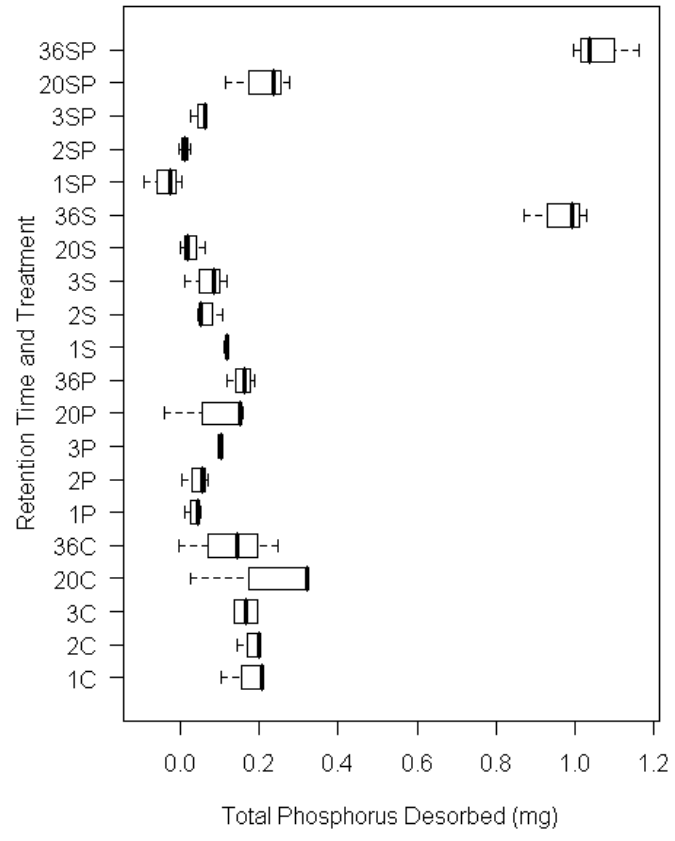

Figure 4. Total desorbed $P$ is shown for the various BRWC treatments and retention times. Each box plot depicts: Q1 - (1.5 $\times I Q R), ~ Q 1$, median, Q3, and $\mathrm{Q3}+(1.5 \times \mathrm{IQR})$. The $y$-axis notation includes the retention time in days followed by the cell treatment $(C=$ control, $S=$ sugar, $P=$ pond surface water, and $\mathrm{SP}=$ sugar and pond surface water).

The $\mathrm{P}$ desorptions in these two treatments were not statistically different, indicating that any microbial culture gained from a surface runoff sample was not necessary to achieve $\mathrm{P}$ release.

\section{Total Dissolved Iron}

An analysis of TDI in all groups provides another significant difference between treatments $(p=4.33 \mathrm{E}-5$; Kruskal test), with pairwise multiple comparisons indicating again that the $36 \mathrm{~d}$ sugar solution treatment and the $36 \mathrm{~d}$ sugar solution and surface water treatment were significantly different from all other treatments (fig. 5). Unlike the results for TDP, TDI in the $36 \mathrm{~d}$ sugar solution treatment was significantly higher than TDI in the $36 \mathrm{~d}$ sugar solution and surface water treatment. A possible explanation for this result is a higher sugar concentration providing more carbon for additional growth and metabolism of Fe-reducing microorganisms.

No statistical difference in initial $\mathrm{P}$ adsorption between treatment groups was observed $(\mathrm{p}=0.907$; Kruskal test; fig. 6). The time before significant $\mathrm{Fe}$ reduction and $\mathrm{P}$ desorption took place $(20 \mathrm{~d}<t<36 \mathrm{~d})$ agrees with the results from the FTWC. Percent desorption for the $36 \mathrm{~d}$ treatments with sugar solution and with sugar solution and surface water had a mean of $32.7 \%$ with a standard deviation of $4.42 \%$.

\section{SUMmARY OF FTWC AND BRWC RESULTS}

The results from the FTWC indicate that a large percentage of $\mathrm{P}$ adsorbed to substrates during filtration of water with typical stormwater concentrations of $\mathrm{P}$ can be released through a facilitated $\mathrm{Fe}$ reduction process. Results from the BRWC further indicate that the addition of a carbon source in excess of that available in a surface water sample was necessary, but that inclusion of the surface water to provide microbial seeding was not necessary to initiate Fe reduction. 


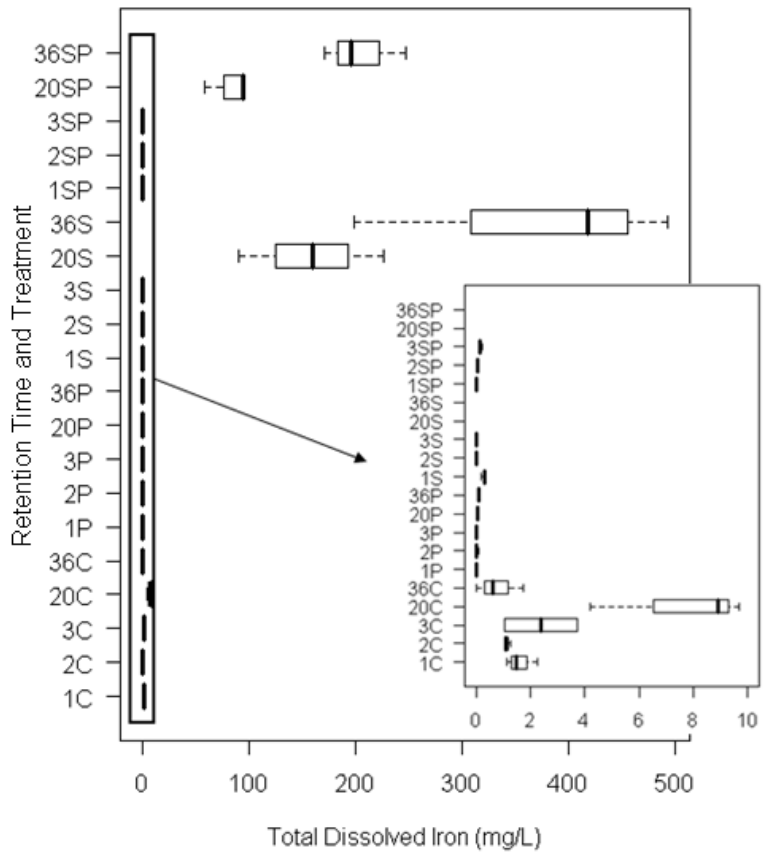

Figure 5. TDI is shown for the various BRWC treatments and retention times. Each box plot depicts: Q1 - $(1.5 \times I Q R), Q 1$, median, Q3, and Q3 + $(1.5 \times I Q R)$. The $y$-axis notation includes the retention time in days followed by the cell treatment $(C=$ control, $S=$ sugar, $P=$ pond surface water, and $\mathrm{SP}$ = sugar and pond surface water).

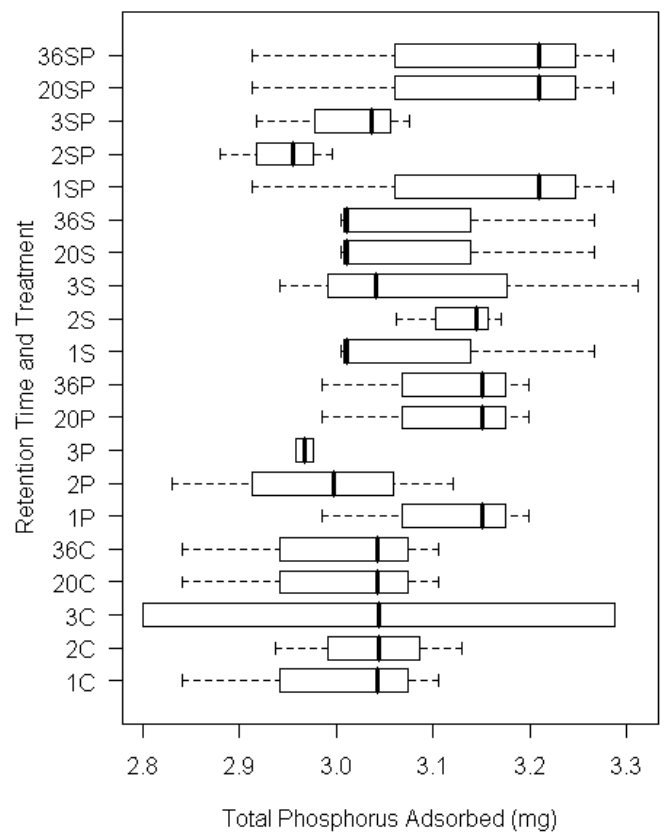

Figure 6. Total initially adsorbed is shown $P$ for the various BRWC treatments and retention times. Each box plot depicts: Q1 - (1.5×IQR), Q1, median, $\mathrm{Q3}$, and $\mathrm{Q3}+(1.5 \times \mathrm{IQR})$. The $y$-axis notation includes the retention time in days followed by the cell treatment $(C=\operatorname{control}, \mathrm{S}=\operatorname{sugar}, \mathrm{P}=$ pond surface water, and $\mathrm{SP}=$ sugar and pond surface water).

\section{Conclusions}

Results obtained from both FTWC and BRWC indicate a significant ability to release previously sequestered $\mathrm{P}$ within substrates by microbial reduction of Fe. The following conclusions can be made based on the above results:

- Fe-reducing microorganisms are naturally present in the sand media, and inclusion of the surface water sample did not significantly increase the amount of $\mathrm{Fe}$ reduced or P released.

- Addition of a carbon source was necessary to promote microbial reduction of Fe.

- Dissolved P is positively correlated with dissolved Fe, indicating that release of previously sequestered $\mathrm{P}$ in substrates is released during $\mathrm{Fe}$ reduction.

- The two-region relationship between P release and Fe reduction indicates that $P$ release was attenuated below a threshold of Fe dissolution, possibly due to availability for resorption while some $\mathrm{Fe}^{3+}$ coatings remained on substrate surfaces.

- A high percentage of previously adsorbed P can be released as a result of microbial $\mathrm{Fe}$ reduction, although the process was slower by an order of magnitude than adsorption for the same P load.

- The P concentration in rejuvenating cells can increase by orders of magnitude over the influent $\mathrm{P}$ loading concentrations.

While the dissolution of $\mathrm{Fe}$ and subsequent release of $\mathrm{P}$ in the FTWC continued to increase throughout the study period, it can be assumed that the TDP concentrations will reach a maximum (at least upon complete release of all available P). Given the results, it is feasible that the majority of previously adsorbed $\mathrm{P}$ in substrates can be desorbed by this method. However, to achieve efficient cycling between rejuvenation and filtration cycles, the rejuvenation time must be decreased, necessitating further research to facilitate faster $\mathrm{Fe}$ reduction. Once $\mathrm{P}$ is desorbed, two additional challenges present opportunities for further research: the highconcentration dissolved $\mathrm{P}$ must be either removed in solution or precipitated as a solid for harvest, and the sand must be recoated with Fe to prepare the substrate for continued adsorption of P. In the context of the larger research project, this study has provided further indication that a BMP based on the rejuvenation of substrate sorption capacity by microbial reduction is a practical method to improve nutrient management in urban areas and reduce the environmental and economic impacts of eutrophication.

\section{ACKNOWLEDGEMENTS}

The authors would like to thank the National Science Foundation for providing support for the students who worked on this project as a part of a NSF Research Experiences for Undergraduates grant (\#0649079). In addition, the authors would like to specifically acknowledge assistance from exceptional faculty (Dr. Tess Wynn and Dr. Daniel Gallagher), staff (Laura Teany), and students (Molly Julian, Gina Hayes, Yemi Ojumu, Cody Newbill, Sarah Brahman, Jonathan Pennington, and Alyse Egner) who were all critical to the success of this study. 


\section{REFERENCES}

Abelson, P. H. 1999. A potential phosphate crisis. Science 283 (5410): 2015.

Aldous, A. R., C. B. Craft, S. J. Carla, M. J. Barry, and B. B. Leslie. 2007. Soil phosphorus release from a restoration wetland, Upper Klamath Lake, Oregon. Wetlands 27(4): 1025-1035.

Baker, B. J., K. W. King, and H. A. Torbert. 2007. Runoff losses of dissolved reactive phosphorus from organic fertilizer applied to sod. Trans. ASABE 50(2): 449-454.

Brady, N. C., and R. R. Weil. 2002. The Nature and Properties of Soils. Upper Saddle River, N.J.: Prentice Hall.

Carleton, J. N., T. J. Grizzard, A. N. Godrej, H. E. Post, L. Lampe, and P. P. Kenel. 2000. Performance of a constructed wetlands in treating urban stormwater runoff. Water Environ. Res. 72(3): 295-304

Coveney, M. F., D. L. Stites, E. F. Lowe, and R. C. Battoe. 2002. Nutrient removal from eutrophic lake water by wetland filtration. Ecol. Eng. 19(2): 141-159.

Drizo, A., Y. Comeau, C. Forget, and R. P. Chapuis. 2002. Phosphorus saturation potential: A parameter for estimating the longevity of constructed wetland systems. Environ. Sci. Tech. 36(21): 4642-4648.

Griffioen, J. 2006. Extent of immobilization of phosphate during aeration of nutrient-rich, anoxic groundwater. J. Hydrol. 320(3-4): 359-369.

Hammer, D. 1992. Designing constructed wetlands systems to treat agricultural nonpoint source pollution. Ecol. Eng. 1(1-2): 49-82.

Hogan, D. M., and M. R. Waldbridge. 2007. Best management practices for nutrient and sediment retention in urban stormwater runoff. J. Environ. Qual. 36(2): 386-395.

Hunt, W. F., and A. Wossink. 2003. The Economics of Structural Stormwater BMPs in North Carolina. UNC-WRRI-2003-344. Raleigh, N.C.: University of North Carolina, Water Resources Research Institute.

Kadlec, R. H. 2000. The inadequacy of first-order treatment wetland models. Ecol. Eng. 15(1-2): 105-119.

Kadlec, R. H. 2005. Phosphorus removal in emergent free surface wetlands. J. Environ. Sci. Health A 40(6): 1293-1306.

Kadlec, R. H., and S. D. Wallace. 2009. Treatment Wetlands. Boca Raton, Fla.: CRC Press.

Keppler, A. M., and J. F. Martin. 2008. Investigating the performance of a laboratory-scale ecological system to treat dairy wastewater. Trans. ASABE 51(5): 1837-1846.

Komatsu, E., T. Fukushima, and H. Shiraishi. 2006. Modeling of P dynamics and algal growth in a stratified reservoir: Mechanisms of $\mathrm{P}$ cycle in water and interaction between overlying water and sediment. Ecol. Model. 197(3-4): 331-349.

Lantzke, I. R., A. D. Heritage, G. Pistillo, and D. S. Mitchell. 1998. Phosphorus removal rates in bucket size planted wetlands with a vertical hydraulic flow. Water Res. 32(4): 1280-1286.

Lantzke, I. R., D. S. Mitchell, A. D. Heritage, and K. P. Sharma. 1999. A model of factors controlling orthophosphate removal in planted vertical flow wetlands. Ecol. Eng. 12(1): 93-105.
Lovely, D. R., E. J. P. Phillips, and D. J. Lonergan. 1991. Enzymatic versus nonenzymatic mechanisms for Fe(III) reduction in aquatic sediments. Environ. Sci. Tech. 25(6): 1062-1067.

Luederitz, V., and F. Gerlach. 2002. Phosphorous removal in different constructed wetlands. Acta Biotech. 22(1-2): 91-99.

Luederitz, V., E. Eckert, M. Lange-Weber, A. Lange, and R. M. Gersberg. 2001. Nutrient removal efficiency and resource economics of vertical flow and horizontal flow constructed wetlands. Ecol. Eng. 18(2): 157-171.

McBride, M. B. 1994. Environmental Chemistry of Soils. New York, N.Y.: Oxford University Press.

McGechan, M. B., and D. R. Lewis. 2002. Sorption of phosphorus by soil: Part 1. Principles, equations, and models. Biosys. Eng. 82(1): 1-24.

McMahon, P. B., and F. H. Chapelle. 1991. Microbial production of organic acids in aquitard sediments and its role in aquifer geochemistry. Nature 349(6306): 233-235.

Novotny, V. 2003. Water Quality. Hoboken, N.J.: John Wiley and Sons.

Rosenquist, S. E., W. C. Hession, M. J. Eick, and D. H. Vaughan. 2010. Variability in adsorptive phosphorus removal by structural stormwater best management practices. Ecol. Eng. 36(5): 664-671.

Saavedra, C., and A. Delgado. 2005. Iron-related phosphorus in eroded sediments from agricultural soils of Mediterranean areas. Geoderma 125(1-2): 1-9.

Scheibe, T. D., Y. Fang, C. J. Murray, E. E. Roden, and J. Chen. 2006. Transport and biogeochemical reaction of metals in a physically and chemically heterogeneous aquifer. Geosphere 2(4): 220-235.

R Development Core Team. 2009. R: A language and environment for statistical computing. Vienna, Austria: R Foundation for Statistical Computing.

Tenenbaum, D. J. 2004. Constructed wetlands: Borrowing a concept from nature. Environ. Health Perspect. 112(1): 44-48.

USEPA. 1994. EPA Method 200.7: Determination of metals and trace elements in water and wastes by inductively coupled plasma-atomic emission spectrometry. Cincinnati, Ohio: U.S. Environmental Protection Agency, Office of Research and Development.

Vymazal, J. 2005. Horizontal subsurface flow and hybrid constructed wetlands systems for wastewater treatment. Ecol. Eng. 25(5): 478-490.

White, J. R., L. M. Gardner, M. Sees, and R. Corstanje. 2008. The short-term effects of prescribed burning on biomass removal and the release of nitrogen and phosphorus in a treatment wetland. $J$. Environ. Qual. 37(6): 2386-2391.

Wilson, G. V., F. E. Rhoton, and H. M. Selim. 2004. Modeling the impact of ferrihydrite on adsorption-desorption of soil phosphorus. Soil Sci. 169(4): 271-281.

Zhang, J., and X. Huang. 2007. Relative importance of solid-phase phosphorus and iron on the sorption behavior of sediments. Environ. Sci. Tech. 41(8): 2789-2795. 